\title{
Evidence of disease control: a realistic concept beyond NEDA in the treatment of multiple sclerosis [version 1; peer review:
}

\section{2 approved]}

\author{
Ana C. Londoño (i)1, Carlos A. Mora (iD2 \\ ${ }^{1}$ Instituto Neurológico de Colombia (INDEC), Medellín, Colombia \\ ${ }^{2}$ Department of Neurology, MedStar Georgetown University Hospital, Washington, DC, USA
}

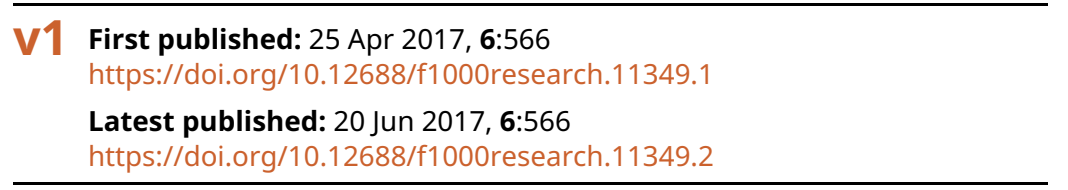

\section{Abstract}

Although no evidence of disease activity (NEDA) permits evaluation of response to treatment in the systematic follow-up of patients with multiple sclerosis (MS), its ability to accomplish detection of surreptitious activity of disease is limited, thus being unable to prevent patients from falling into a non-reversible progressive phase of disease. A protocol of evaluation based on the use of validated biomarkers that is conducted at an early stage of disease would permit the capture of abnormal neuroimmunological phenomena and lead towards intervention with modifying therapy before tissue damage has been reached.

\section{Keywords}

axonopathy, biomarkers, MRI, MS, NEDA, neurodegeneration, neuroinflammation

\section{Open Peer Review \\ Approval Status \\ 1 2 \\ version 2 \\ (revision) \\ 20 Jun 2017 \\ version 1 \\ 25 Apr 2017

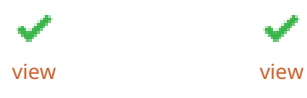 \\ 1. Hans Lassmann, Medical University of Vienna, Vienna, Austria \\ 2. Declan Chard ID, University College London, London, UK}

Any reports and responses or comments on the article can be found at the end of the article.

Corresponding author: Carlos A. Mora (cxmz@gunet.georgetown.edu)

Competing interests: CAM is a member of the Data \& Safety Monitoring Board for the NINDS/NIH study NS003055-08/NS003056-08. He received no compensation for his participation in that study. ACL does not report any competing interests.

Grant information: The author(s) declared that no grants were involved in supporting this work.

Copyright: $\odot 2017$ Londoño AC and Mora CA. This is an open access article distributed under the terms of the Creative Commons Attribution License, which permits unrestricted use, distribution, and reproduction in any medium, provided the original work is properly cited.

How to cite this article: Londoño AC and Mora CA. Evidence of disease control: a realistic concept beyond NEDA in the treatment of multiple sclerosis [version 1; peer review: 2 approved] F1000Research 2017, 6:566 https://doi.org/10.12688/f1000research.11349.1 First published: 25 Apr 2017, 6:566 https://doi.org/10.12688/f1000research.11349.1 


\section{Introduction}

Immunomodulatory therapies used in the treatment of patients with the clinical isolated syndrome (CIS) of multiple sclerosis (MS) and early relapsing remitting multiple sclerosis (RRMS), as well as the autologous hematopoietic stem cell transplant (aHSCT) used in the treatment of the catastrophic form of the disease, have accomplished a reduction in clinical relapses, a halting in progression toward neurological disability and have demonstrated a reduction of disease activity in MRI scans. This progress has led to the emergence of the 'no evidence of disease activity' (NEDA) composite which evaluates the response to these therapies in clinical studies, but its systematic application and utility in the clinical setting have not been established ${ }^{1}$. NEDA could be considered not only a goal of therapy, but also as an indicator of prognosis and a tool that measures the effect of the medication currently being used ${ }^{2}$. We propose a more aggressive approach that challenges the current application of NEDA.

\section{Fragility of the NEDA composite}

In a cohort of 219 patients with either CIS or RRMS, 60 of 218 $(27.5 \%)$ maintained NEDA status at 2 years, whereas only 17 of $216(7.9 \%)$ had NEDA at 7 years. NEDA status at 2 years had a positive predictive value of $78.3 \%$ for no progression of disease at 7 years, demonstrating that it may be optimal in terms of prognostic value in the long term ${ }^{1}$. This study disclosed a dissociation between clinical and MRI-followed disease activity, with a more prevalent loss of NEDA status determined by MRI changes at onset, followed by clinical relapses without presence of new lesions or changes in the previously existing lesions at later stages. The loss of NEDA status due to changes in expanded disability status scale (EDSS), which is a method of rating impairment in neurological functions excluding cognition, was infrequent ${ }^{1}$. These findings support a decrement in the inflammatory activity of disease as duration of disease increases, and the possibility of recruitment of additional neuronal pathways and/or a cortical remodeling that could compensate for the loss of function ${ }^{3}$. Also, cognitive impairment may affect more than $82 \%$ of the patients with MS from early stages of the disease, affecting cognitive performance and quality of life ${ }^{3}$. Damasceno et al. proposed that NEDA should also take into consideration other important measures of the patients' neurological condition, such as their cognitive status and the volumetric analysis of the brain, converting NEDA into a completely effective tool for therapy evaluation. In their cohort of 42 patients with RRMS treated either with beta-interferon or glatiramer acetate, NEDA status was accomplished in only $30.8 \%$ of patients, with worsening of more than two cognitive domains in $58.3 \%$ of the NEDA group, and with evidence of cortical thinning and higher thalamus volume decrease in patients with MRI activity ${ }^{4}$. Studies using drugs known to produce a better therapeutic effect in multiple sclerosis, such as natalizumab and alemtuzumab, have disclosed loss of the NEDA status after 2 years of initiation of therapy in $37 \%$ and $39 \%$ of the treated patients, respectively ${ }^{4}$. Currently, aHSCT is the only therapeutic approach that has accomplished NEDA status after 3 years in $75 \%$ of patients ${ }^{5}$. Giovannoni has recently discussed the adaptation of NEDA to the type of the therapeutic regime, and has considered three scenarios. These include a) no treatment, b) maintenance/escalation of disease-modifying therapy, and c) use of induction therapies (such as alemtuzumab, cladribine and aHSCT) establishing a baseline according to the pharmacodynamics of each drug available ${ }^{2}$.

Although progression of disease, which reflects the neurode generative component of MS, is expected to be reflected by the EDSS score in the actual concept of NEDA, evidence has shown that the T25FW (timed 25-foot walk) test gave better documentation of clinical progression ${ }^{1}$. Considering the use of NEDA, Dadalti Fragoso discussed the difficulties encountered when using EDSS to objectively document patient functionality in different areas. Clinical manifestations such as fatigue or sensitivity to heat are not considered, there is an inconvenient variability among evaluators with differences up to 2.0 points for EDSS and 3.0 points for functional system evaluation, and there is the disadvantage of having the patient, and not the evaluator, reporting the ability to walk $500 \mathrm{~m}$ or 300 meters $^{6}$. These studies have shown that, in a high percentage of patients, activity of disease was present at baseline and could not be detected by NEDA thus resulting in a delayed therapeutic intervention and irreparable damage of the central nervous system (CNS).

\section{Background activity beyond the surveillance of NEDA}

The term 'minimal evident disease activity' (MEDA) has been applied to MS patients who have been apparently stable in comparison to patients with higher level of activity in the short to intermediate term ${ }^{2}$. Thus, beyond documenting NEDA we mostly need to achieve documentation of the unnoticed surreptitious activity of disease which remains despite treatment. The determination of biomarkers of inflammation and neurodegeneration in body fluids, combined with the use of non-conventional MRI with the ability to detect changes in the normal appearing brain tissue, could assist in the detection of a sequence of cellular and molecular events, inside and out of the CNS, that occur before fulfilling the current definition of NEDA composite. Multiple biomarkers have been identified in MS, but their validation and clinical application have not been established ${ }^{7,8}$. Teunissen recently discussed the use of biomarkers for MS such as $\mathrm{N}$-acetylaspartate (representing mitochondrial dysfunction and/or neuro-axonal loss), chitinase 3 likeprotein 1 (meaning reactive astrogliosis and microglial activity), neurofilament light chain (related to axonal loss) and glial fibrillary acidic protein (representing astrocytic cytoskeleton injury). They have been validated in at least two independent cohorts, and evaluation of their expression could be a useful tool at the time of diagnosis of MS, and during follow-up after the administration of disease modifying therapy ${ }^{9}$.

Bonnan et al. have recently suggested that NEDA cannot predict sustained remission or complete recovery of disease, and proposed a 'disease free status score' be established, based on whether or not there is biological activity of disease, by measuring the level of biomarkers in $\mathrm{CSF}^{10}$. Taking into consideration that, at present, there are no therapeutic agents available that would be able to offer a cure for MS, a disease free status score could create confusion on top of becoming a non-realistic concept. We support the concept that the methodology used to determine the stage of disease should be based on the measuring of the level of biomarkers involved in 
the inflammatory and neurodegenerative events of disease, not only by CSF analysis but also with non-invasive available tools such as PET-CT and non-conventional MRI to evaluate the normal appearing brain tissue $\mathrm{e}^{11-16}$.

\section{Goals and conclusion}

In the systematic evaluation of the patient with MS, the primary goal should be the monitoring of evidence of disease control with biomarkers in order to:

\section{Prevent clinical relapses}

2. Confirm absence of changes suggestive of progression of the disease in pre-existing lesions, including checking for presence of new lesions or atrophy detected by MRI; and

3. Prevent progression toward disability

By supporting a pro-active management of disease, avoiding brain tissue injury instead of controlling existing inflammation and/or neurodegeneration, this approach is promoting a personalized management of disease ${ }^{17}$.

Early treatment of patients with CIS has led to the identification of a therapeutic window that, with current interventions, would be able to slow down progression toward higher scores in EDSS evaluation ${ }^{3}$. Taking into consideration the recent significant attention given to novel monoclonal antibody therapies (including alemtuzumab, rituximab, ocrelizumab, daclizumab) $)^{18-21}$ and stem cell therapies (aHSCT) ${ }^{22}$, our most immediate goal should involve searching for strategic interventions to control both inflammation and neurodegeneration, hopefully reaching a stage of prolonged remission in selected patients. Taking into consideration that NEDA status is currently able to switch on red flags only when tissue damage has already occurred in the CNS, we believe that 'evidence of disease control' will be accomplished through a better defined, convincing and more realistic monitoring of validated biomarkers.

\section{Acknowledgements}

The authors thank Dr. Robert K. Shin (Department of Neurology, MedStar Georgetown University Hospital) for review of the initial draft of this manuscript.

\section{Author contributions}

ACL and CAM equally contributed to the study concept and to drafting and critically revising the manuscript. Both ACL and CAM agreed to the final content of the manuscript.

\section{Competing interests}

CAM is a member of the Data \& Safety Monitoring Board for the NINDS/NIH study NS003055-08/NS003056-08. He received no compensation for his participation in that study. ACL does not report any competing interests.

\section{Grant information}

The author(s) declared that no grants were involved in supporting this work.
1. Rotstein DL, Healy BC, Malik MT, et al:: Evaluation of no evidence of disease activity in a 7-year longitudinal multiple sclerosis cohort. JAMA Neurol. 2015; 72(2): 152-158.

PubMed Abstract | Publisher Full Text

2. Giovannoni G: Multiple sclerosis should be treated using a step-down strategy rather than a step-up strategy-YES. Mult Scler. 2016; 22(11): 1397-1400. PubMed Abstract | Publisher Full Text

3. Ziemssen T, Derfuss T, de Stefano N, et al.: Optimizing treatment success in multiple sclerosis. J Neurol. 2016; 263(6): 1053-1065. PubMed Abstract | Publisher Full Text | Free Full Text

4. Damasceno A, Damasceno BP, Cendes F: No evidence of disease activity in multiple sclerosis: Implications on cognition and brain atrophy. Mult Scler. 2016; 22(1): 64-72.

PubMed Abstract | Publisher Full Text

5. Sormani MP, Muraro PA, Saccardi R, et al.: NEDA status in highly active MS can be more easily obtained with autologous hematopoietic stem cell transplantation than other drugs. Mult Scler. 2017; 23(2): 201-204. PubMed Abstract | Publisher Full Text

6. Dadalti Fragoso Y: Why some of us do not like the expression "no evidence of disease activity" (NEDA) in multiple sclerosis. Mult Scler Relat Disord. 2015; 4(4): 383-4.

PubMed Abstract | Publisher Full Text

7. Comabella M, Montalban X: Body fluid biomarkers in multiple sclerosis. Lancet Neurol. 2014; 13(1): 113-26.

PubMed Abstract | Publisher Full Text

8. Katsavos S, Anagnostouli M: Biomarkers in Multiple Sclerosis: An Up-to-Date Overview. Mult Scler Int. 2013; 2013: 340508 PubMed Abstract | Publisher Full Text | Free Full Text

9. Teunissen CE, Malekzadeh A, Leurs C, et al:: Body fluid biomarkers for multiple sclerosis--the long road to clinical application. Nat Rev Neurol. 2015; 11(10): 585-96.

PubMed Abstract | Publisher Full Text

10. Bonnan M, Marasescu R, Demasles S, et al.: No evidence of disease activity (NEDA) in MS should include CSF biology - Towards a 'Disease-Free Status Score'. Mult Scler Relat Disord. 2017; 11: 51-55. PubMed Abstract | Publisher Full Text

11. Datta G, Violante IR, Scott G, et al.: Translocator positron-emission tomography and magnetic resonance spectroscopic imaging of brain glial cell activation in multiple sclerosis. Mul Scler. 2016; 1352458516681504. PubMed Abstract | Publisher Full Text

12. Poutiainen $\mathrm{P}$, Jaronen M, Quintana FJ, et al.: Precision Medicine in Multiple Sclerosis: Future of PET Imaging of Inflammation and Reactive Astrocytes. Front Mol Neurosci. 2016; 9: 85.

PubMed Abstract | Publisher Full Text | Free Full Text

13. Airas $L$, Rissanen $E$, Rinne J: Imaging of microglial activation in MS using PET: Research use and potential future clinical application. Mult Scler. 2017; 23(4): 496-504.

PubMed Abstract | Publisher Full Text

14. Albrecht DS, Granziera C, Hooker JM, et al:: In Vivo Imaging of Human Neuroinflammation. ACS Chem Neurosci. 2016; 7(4): 470-83. PubMed Abstract | Publisher Full Text

15. Enzinger $\mathrm{C}$, Barkhof $\mathrm{F}$, Ciccarelli $\mathrm{O}$, et al.: Nonconventional MRI and microstructural cerebral changes in multiple sclerosis. Nat Rev Neurol. 2015; 11(12): 676-86

PubMed Abstract | Publisher Full Text

16. Londoño AC, Mora CA: Nonconventional MRI biomarkers for In vivo monitoring of pathogenesis in multiple sclerosis. Neurol Neuroimmunol Neuroinflamm. 2014; 1(4): e45.

PubMed Abstract | Publisher Full Text | Free Full Text 
17. Hood L: Systems biology and p4 medicine: past, present, and future. Rambam Maimonides Med J. 2013; 4(2): e0012. PubMed Abstract | Publisher Full Text | Free Full Text

18. Riera R, Porfírio GJ, Torloni MR: Alemtuzumab for multiple sclerosis. Cochrane Database Syst Rev. 2016; 4: CD011203. PubMed Abstract | Publisher Full Text

19. de Flon $P$, Laurell K, Söderström L, et al.: Improved treatment satisfaction after switching therapy to rituximab in relapsing-remitting MS. Mult Scler. 2016; 1352458516676643.

PubMed Abstract | Publisher Full Text
20. Montalban X, Hauser SL, Kappos L, et al:: Ocrelizumab versus Placebo in Primary Progressive Multiple Sclerosis. N Engl J Med. 2017; 376(3): 209-220. PubMed Abstract | Publisher Full Text

21. Herwerth $M$, Hemmer B: Daclizumab for the treatment of relapsing-remitting multiple sclerosis. Expert Opin Biol Ther. 2017; 1-7. PubMed Abstract | Publisher Full Text

22. Muraro PA, Pasquini M, Atkins $\mathrm{HL}$, et al.: Long-term Outcomes After Autologous Hematopoietic Stem Cell Transplantation for Multiple Sclerosis. JAMA Neurol. 2017; 74(4): 459-469.

PubMed Abstract | Publisher Full Text 


\section{Open Peer Review}

\section{Current Peer Review Status:}

\section{Version 1}

Reviewer Report 24 May 2017

https://doi.org/10.5256/f1000research.12251.r22238

(C) 2017 Chard D. This is an open access peer review report distributed under the terms of the Creative Commons Attribution License, which permits unrestricted use, distribution, and reproduction in any medium, provided the original work is properly cited.

\section{Declan Chard}

Institute of Neurology, University College London, London, WC1N 3BG, UK

With a view to preventing disability by optimising treatment decisions, there has been growing interest in the concept of 'no evidence of disease activity' (NEDA) outcomes. In their opinion article Londoño and Moro consider the complexities of NEDA definitions and the role of such scores in clinical practice.

They authors remind us that the definition of NEDA as a marker of treatment failure and predictor of future clinical outcomes is subject to debate. While considering definitions of NEDA, it is perhaps also worth mentioning the work of Rio and colleagues (Multiple Sclerosis. 2009 Jul;15(7):848-53.), which suggests that radiological evidence of disease activity does not necessarily translate into a significantly increased short-term risk of clinical disease activity.

The authors consider the limitations of using EDSS scores as a marker of clinical progression, to which could perhaps be added the difficulties determining if an episode of symptoms is due to inflammation (Tallantyre et al. 2015 ${ }^{1}$ ) They also highlight that MRI measures of lesion accrual or brain atrophy may still overlook clinically relevant disease activity, and that fluid biomarkers may also provide relevant indicators of evolving pathology.

On reviewing the work of Rotstein et al. $(2015)^{2}$ the authors note that 'loss of NEDA status due to changes in expanded disability status scale (EDSS), which is a method of rating impairment in neurological functions excluding cognition, was infrequent.' While less frequent than relapses, the figures for people with established MS shown in Table 2 (if I have read these correctly) suggest that by 7 years about $20 \%$ of those with evidence of clinical activity had progression without relapses (74\% had evidence of either progression or relapse, $59 \%$ had had a relapse, implying that $15 \%$ had progression without a relapse).

The authors 'support the concept that the methodology used to determine the stage of disease should be based on the measuring of the level of biomarkers involved in the inflammatory and neurodegenerative events of disease'. This touches on an interesting line of thought on differentiating MS subtypes, which clinically can be difficult (and I am not aware of any biomarkers 
that substantially improve on this on a person-by-person basis), and how this relates to definitions of NEDA or ongoing clinically relevant disease activity. With regard to clinical outcomes, while NEDA definitions include both relapses and disability progression, the two may not be closely linked (Vukusic and Confavreux $2007^{3}$ ). As such, predictors of the risk of future relapses and risk of non-relapse associated progression may differ, and similarly composite scores designed to predict these outcomes may not necessarily be the same, or applicable to all MS subtypes equally. It would be interesting to hear more of the authors' thoughts on this.

In the abstract, the authors state that 'A protocol of evaluation based on the use of validated biomarkers that is conducted at an early stage of disease would permit the capture of abnormal neuroimmunological phenomena and lead towards intervention with modifying therapy before tissue damage has been reached.' However, there are perhaps some qualifications to this if a biomarker protocol is going to be useful in clinical practice, for example that the biomarkers used need to be (alone or in combination) reliable markers of disease activity at the level of individual people with MS, and that the pathological processes they reflect can be effectively targeted by treatments.

\section{References}

1. Tallantyre EC, Causon EG, Harding KE, Pickersgill TP, et al.: The aetiology of acute neurological decline in multiple sclerosis: experience from an open-access clinic.Mult Scler. 2015; 21 (1): 67-75

PubMed Abstract | Publisher Full Text

2. Rotstein DL, Healy BC, Malik MT, Chitnis T, et al.: Evaluation of no evidence of disease activity in a 7-year longitudinal multiple sclerosis cohort.JAMA Neurol. 2015; 72 (2): 152-8 PubMed Abstract | Publisher Full Text

3. Vukusic $S$, Confavreux C: Natural history of multiple sclerosis: risk factors and prognostic indicators.Curr Opin Neurol. 2007; 20 (3): 269-74 PubMed Abstract | Publisher Full Text

\section{Is the topic of the opinion article discussed accurately in the context of the current} literature?

Yes

Are all factual statements correct and adequately supported by citations? Partly

\section{Are arguments sufficiently supported by evidence from the published literature?} Yes

Are the conclusions drawn balanced and justified on the basis of the presented arguments? Yes

Competing Interests: Declan Chard has received research support from the MS Society of Great Britain and Northern Ireland, and the National Institute for Health Research University College London Hospitals Biomedical Research Centre. He has received honoraria (paid to his employer) from Ismar Healthcare NV, Swiss MS Society, Excemed (previously Serono Symposia International Foundation), Merck, Bayer and Teva for faculty-led education work; Teva for advisory board work; meeting expenses from Merck, Teva, Novartis, the MS Trust and National MS Society; and has 
previously held stock in GlaxoSmithKline.

\section{I confirm that I have read this submission and believe that I have an appropriate level of expertise to confirm that it is of an acceptable scientific standard.}

Author Response 12 Jun 2017

Carlos Mora, Ascension, USA

We strongly appreciate the comments and input provided by the reviewers of the first version of our article. With especial interest in the comments and questions posed by reviewer 2 (Dr Chard) we acknowledge the work of Rio and colleagues (Multiple Sclerosis. 2009 Jul;15(7):848-53) and we take into consideration the fact that although the mentioned study was limited to the effect of one disease modifying agent (IFNb given in four different commercially available preparations) on patients with the relapsing-remitting form of disease [RRMS] it showed that progression in at least two of the three variables analyzed (relapses, increase of disability or MRI activity) after 12 months would correlate with risk of progression of disease in the following years. However, this conclusion cannot be extrapolated to other groups of patients with RRMS who have happened to be treated with other disease modifying agents taking into consideration the different mode of action of these immune-modulators. In relation to the comment on our citation of Rotstein and colleagues (JAMA Neurol. 2015;72(2):152-158. 25531931 10.1001/jamaneurol.2014.3537) we extended the content of the sentence in the text reflecting that the loss of NEDA status due to changes in EDSS was infrequent in comparison to the level of determination provided by the clinical relapsing and imaging-related biomarkers.

As for the invitation to comment on how the different MS sub-types may correlate to definitions of NEDA or ongoing clinically relevant disease activity we concur with the fact that although NEDA definitions include both relapses and disability progression, the two may not be closely linked and, therefore, a different set of biomarkers ought to be validated to determine forthcoming inflammation and/or neurodegeneration. On the other hand, differentiation of sub-types of disease (especially in reference to inflammatory vs. degenerative pathologic processes) will be feasible with the forthcoming application of biomarkers in the MS related clinical practice. NEDA may not be a useful tool for the evaluation of patients with PPMS taking into consideration that this sub-type of MS is characterized by on-going disability and minimal inflammatory activity in MRI. At present, with the development of new medications for the treatment of PPMS, it would be essential to count with measurable biomarkers which would allow the determination of an objective response to therapies.

Competing Interests: No competing interests to disclose 
(c) 2017 Lassmann H. This is an open access peer review report distributed under the terms of the Creative Commons Attribution License, which permits unrestricted use, distribution, and reproduction in any medium, provided the original work is properly cited.

\section{Hans Lassmann}

Center for Brain Research, Medical University of Vienna, Vienna, Austria

This opinion article deals with a highly relevant topic, the validity of the concept of no evidence for disease activity "NEDA" in multiple sclerosis. Prevention of disease progression may possibly be achieved in patients, when treatment completely blocks ongoing disease activity and NEDA has been suggested as a tool to check, whether this is achieved in individual patients. However, clinical detection of disease activity, as suggested in the NEDA concept is far from being complete. Thus, this opinion article suggests to supplement current NEDA criteria with additional para-clinical markers. Such potential biomarkers are non-conventional new MRI sequences, magnetic resonance spectroscopy ( $\mathrm{N}$-acetyl aspartate) for evaluation of mitochondrial injury and biochemical markers such as chitinase 3, neurofilament or glial fibrillary acidic protein in the cerebrospinal fluid. Whether these additional markers will increase the reliability of NEDA criteria, will have to be established in prospective clinical studies. However, so far none of them are perfect para-clinical predictors of disease activity and currently no tools are available to monitor major pathological substrates of disease progression in MS, such as for instance the dynamic development of demyelinating lesions in the cortex, the expansion of pre-existing white matter lesions or the presence of more subtle changes within the normal appearing white and grey matter of the MS brain.

Is the topic of the opinion article discussed accurately in the context of the current literature?

Yes

\section{Are all factual statements correct and adequately supported by citations?} Yes

Are arguments sufficiently supported by evidence from the published literature? Yes

Are the conclusions drawn balanced and justified on the basis of the presented arguments? Yes

Competing Interests: No competing interests were disclosed.

I confirm that I have read this submission and believe that I have an appropriate level of expertise to confirm that it is of an acceptable scientific standard. 
The benefits of publishing with F1000Research:

- Your article is published within days, with no editorial bias

- You can publish traditional articles, null/negative results, case reports, data notes and more

- The peer review process is transparent and collaborative

- Your article is indexed in PubMed after passing peer review

- Dedicated customer support at every stage

For pre-submission enquiries, contact research@f1000.com 